Pak. j. sci. ind. res. Ser. B: biol. sci. 201154 (3) 157-162

\title{
Evaluation of Neutralizing Efficacy of Acorus calamus and Withania somnifera Root Extracts Against Bangarus caeruleus Venom
}

\author{
Subramani Meenatchisundaram ${ }^{\mathrm{a} *}$, Sindhu $\mathrm{u}^{\mathrm{a}}$ and VeerapandianThangapandian ${ }^{\mathrm{b}}$ \\ ${ }^{a}$ Department of Microbiology, Nehru Arts and Science College, Coimbatore, India \\ ${ }^{b}$ Department of Microbiology, Ayya Nadar Janaki Ammal College (Autonomous), Sivakasi, India \\ (received February 14, 2011; revised May 19, 2011; accepted June 18, 2011)
}

\begin{abstract}
Acorus calamus and Withania somnifera root extracts when tested against Bangarus caeruleus venom, both the plant extracts neutralized various pharmacological activities induced by B. caeruleus venom. About $0.12 \mathrm{mg}$ of $A$. calamus and $0.15 \mathrm{mg}$ of $W$. somnifera root extracts completely neutralized the lethal activity of $2 \mathrm{LD}_{50}$ of $B$. caeruleus venom. Various pharmacological activities like haemorrhagic, coagulance, edematic, fibrionlytic and phospholipase activities were effectively neutralized by both the extracts.
\end{abstract}

Keywords: venoms, plant extracts, lethality, Acorus calamus, Withania somnifera, Bangarus caeruleus

\section{Introduction}

Snake bite constitutes major health problem in India. It is estimated that in the annual global burden of 4,21,000 envenomations and 20,000 deaths, India alone contributes 81,000 envenomations and 11,000 deaths. Snake bites are seen often among agricultural workers and among those going to the forests. Based on the above statistics, it appears that every $10 \mathrm{sec}$, one individual is envenomed and one out of four dies due to snake bite (TNHSP, 2008). The male/ female ratio among the victims is approximately $3: 2$. Many deaths occur before the victim reaches the hospital. Common poisonous snakes found in India are Cobra (Naja naja), Krait (Bangarus caeruleus), Russell's viper (Daboia russelli) and saw scaled viper (Echis carinatus). Antivenom immunotherapy is the only specific treatment against snake venom envenomation (Bawaskar, 2004). Antiserum development in animals is time consuming, expensive and requires ideal storage condition. There are various side effects of antivenom drugs such as anaphylactic shock, pyrogen reaction and serum sickness. Most of these symptoms may be due to the action of high concentrations of non-immunoglobulin proteins present in the commercially available horse polyvalent antivenom. Over the years many attempts have been made for the development of snake venom antagonists especially from plants sources. Extracts from plants have been used by traditional healers, especially in tropical areas where there are plentiful plant resources, in therapy for snake bite for a long time (Gomes et al.,

*Author for correspondence; E-mail: drmscbe@gmail.com
2010; Daduang et al., 2005). There have been many attempts to study these plants to assess their effectiveness (Otero et al., 2000; Houghton and Osibogun, 1993).

India has a rich tradition of the usage of medicinal plants. Several snakebite antidotes of plant origin were recommended in old drug recipes for the treatment of snakebite (Alam and Gomes, 2003). The plants Acorus calamus or sweet flag (common name) is a valuable medicinal plant found almost through out India. It possesses anti-inflammatory activity, which is evident from a number of studies. Withania somnifera Dunal (Ashwagandha) belonging to the family Solanaceae has been used in several indigenous Ayurvedic drug preparations for maintaining health as well as for several disease conditions. In herbal medicine, ashwagandha has been traditionally used as alterative, aphrodisiac, nervine tonic, rejuvenator and in inflammation, arthritis and a number of other disorders. Methanolic extracts of Andrographis paniculata and Aristolochia indica possess potent snake venom neutralizing capacity and could potentially be used for therapeutic purposes in case of snakebite envenomation (Meenatchisundaram et al., 2009a). Aqueous extract of Mimosa pudica root possesses compounds, which inhibit the activity of Naja naja and $B$. caerulus venoms (Meenatchisundaram et al., 2009b). The aqueous extract of Mucuna pruriens inhibits the activity of $N$. naja and B. caeruleus venoms (Meenatchisundaram et al., 2010). The present investigation explored the extraction and neutralizing potential of $A$. calamus and $W$. somnifera root extracts which were tested against $B$. caeruleus venom in vivo and in vitro. 


\section{Materials and Methods}

Venom and experimental animals. Freeze-dried snake venom powder of $B$. caeruleus was obtained from Irula's Snake Catchers Industrial Co-operative Society Limited, Chennai and was stored at $4{ }^{\circ} \mathrm{C}$. Male inbred Swiss albino mice 18-20 g were used for the studies. The Institutional Animal Ethics Committee clearance at the Institute of Vector Control and Zoonooses, Hosur, was obtained to conduct the experiment.

Medicinal plants and preparation of extracts. A. calamus and $W$. somnifera plants were obtained from Nehru Herbal Gardens, Coimbatore and the extracts were prepared as stated by Uhegbu et al. (2005) using distilled water as the solvent. $20 \mathrm{~g}$ of powdered sample of the herb was extracted by soaking in $180 \mathrm{~mL}$ of distilled water in a beaker, stirred for about $6 \mathrm{~min}$ and left overnight. Thereafter, the solution was filtered using filter paper Whatman No. 1 and the extract was evaporated to dryness under reduced pressure below $40{ }^{\circ} \mathrm{C}$. The plant extract was expressed in terms of dry weight.

Plant lethality test. The lethal effect of plant extracts was determined by the method of Hung et al. (2004). Five groups of six mice each were used; each group was treated with increasing concentration of plant extract at a final volume of $0.5 \mathrm{~mL}$ by intravenous administration through the tail vein. $\mathrm{LD}_{50}$ was calculated with the confidence limit at $50 \%$ probability by the analysis of deaths occurring within $24 \mathrm{~h}$ of injection.

In vivo assessment of venom toxicity and anti-venom effect of plant extracts. Lethal toxicity of $B$. caeruleus venom. The median lethal dose $\left(\mathrm{LD}_{50}\right)$ of $B$. caeruleus venom was determined according to the method developed by Theakston and Reid (1983). Various concentrations of venom in $0.2 \mathrm{~mL}$ of physiological saline was injected into the tail vein of mice (18-20 g), using groups of 3-5 mice for each venom dose. The $\mathrm{LD}_{50}$ was calculated with the confidence limit at $50 \%$ probability by the analysis of deaths occurring within $24 \mathrm{~h}$ of venom injection. The anti-lethal potentials of A. calamus and $W$. somnifera root extracts were determined against $2 \mathrm{LD}_{50}$ of $B$. caeruleus venom. Different amounts of plant extracts $(\mu \mathrm{L})$ were mixed with $2 \mathrm{LD}_{50}$ of venom sample and incubated at $37^{\circ} \mathrm{C}$ for $30 \mathrm{~min}$ and then injected intravenously. 3-5 mice were used for each antivenom dose. Control mice received the same amount of venom without antivenom (plant extracts). The median effective dose $\left(\mathrm{ED}_{50}\right)$ was calculated from the number of deaths within $24 \mathrm{~h}$ of injection of the venom/antivenom mixture. The $\mathrm{ED}_{50}$ was expressed as $\mu \mathrm{L}$ antivenom/mouse and calculated by probit analysis.

Edema-forming activity of B. caeruleus venom. Minimum edema-forming dose (MED) of $B$. caeruleus venom was determined by the method of Lomonte et al. (1993). Group of four mice were injected subcutaneously in the right footpad with various amounts of venom $(0.25 \mu \mathrm{g}-10 \mu \mathrm{g})$ dissolved in $50 \mu \mathrm{L}$ of phosphate-buffered saline (PBS), $\mathrm{pH}$ 7.2. The left footpad received $50 \mu \mathrm{L}$ of PBS alone (control). Edema was calculated as percentage of increase in the thickness of the right foot injected with venom compared to the left foot. The thickness of each footpad was measured every 30 min after venom injection with a low-pressure spring caliper (Rojas et al., 2005). Minimum edemaforming dose (MED) was the venom dose that induced $30 \%$ edema within $6 \mathrm{~h}$ of venom injection when compared to control. The ability of $A$. calamus and $W$. somnifera root extracts in neutralizing the edemaforming activity was determined by pre-incubating constant amount of venom and various dilutions of A. calamus and $W$. somnifera root extracts and incubating for $30 \mathrm{~min}$ at $37^{\circ} \mathrm{C}$. Then, groups of four mice $(18-20 \mathrm{~g})$ were injected sub-cutaneously in the right footpad with $50 \mu \mathrm{L}$ of the mixtures, containing venom/plant extracts, whereas the left footpad received $50 \mu \mathrm{L}$ of PBS alone. Control mice were injected with venom in the right footpad and $50 \mu \mathrm{L}$ of PBS in the left footpad. Edema evaluated one hour after injection as described by Yamakawa et al. (1976) and was expressed as the percentage increase in thickness of the right footpad compared to the right footpad of the control mice.

Haemorrhagic activity. Minimum haemorrhagic dose (MHD) of B. caeruleus venom was determined by the described method of Theakston and Reid (1983). Minimum haemorrhagic dose was defined as the least amount of venom which when injected intradermaly (i.d.) into mice results in a haemorrhagic lesion of $10 \mathrm{~mm}$ diameter in $24 \mathrm{~h}$. Neutralization of the haemorrhagic activity was estimated by mixing a fixed amount of venom with different amounts of $A$. calamus and $W$. somnifera root extracts. The plant extract-venom mixture was incubated at $37^{\circ} \mathrm{C}$ for $1 \mathrm{~h}$ and $0.1 \mathrm{~mL}$ of the mixture was injected intradermaly into mice. The haemorrhagic lesion was estimated after $24 \mathrm{~h}$.

In vitro assessment of venom toxicity and anti-venom efficacy. Phospholipase activity. Phospholipase A2 activity was measured using an indirect haemolytic 
assay on agarose-erythrocyte-egg yolk gel plate by the method described by Gutierrez et al. (1988). Increasing concentrations of $B$. caeruleus venom $(\mu \mathrm{g})$ was added to $3 \mathrm{~mm}$ wells in agarose gels $(0.8 \%$ in PBS, $\mathrm{pH} 8.1)$ containing $1.2 \%$ sheep erythrocytes, $1.2 \%$ egg yolk as a source of lecithin and $10 \mathrm{mM} \mathrm{CaCl}$. Slides were incubated at $37{ }^{\circ} \mathrm{C}$ overnight and the diameters of the haemolytic halos were measured. Control wells contained $15 \mu \mathrm{L}$ of saline. The minimum indirect haemolytic dose (MIHD) corresponds to a concentration of venom, which produces a haemolytic halo of $11 \mathrm{~mm}$ diameter. The efficacy of $A$. calamus and $W$. somnifera root extracts in neutralizing the phospholipase activity was assessed by mixing the same amount of venom $(\mu \mathrm{g})$ with different amounts of plant extracts $(\mu \mathrm{L})$ and incubated for $30 \mathrm{~min}$ at $37^{\circ} \mathrm{C}$. Then, aliquots of $10 \mu \mathrm{L}$ of the mixtures were added to wells in agarose-egg yolk-sheep erythrocyte gels. Control samples contained venom without plant extract. Plates were incubated at $37{ }^{\circ} \mathrm{C}$ for $20 \mathrm{~h}$. Neutralization was expressed as the ratio $\mathrm{mg}$ antibodies/mg venom able to reduce by $50 \%$ the diameter of the haemolytic halo as compared to the effect induced by venom alone.

Procoagulant activity. The procoagulant activity was assessed according to the method described by Theakston and Reid (1983) modified by Laing et al. (1992). Various amounts of venom dissolved in $100 \mu \mathrm{L}$ PBS ( $\mathrm{pH}$ 7.2) was added to human citrated plasma at $37^{\circ} \mathrm{C}$. Coagulation time was recorded and the minimum coagulant dose (MCD) was determined as the venom concentration, which induced clotting of plasma within $60 \mathrm{sec}$. Plasma incubated with PBS alone served as control. In neutralization assays, constant amount of venom was mixed with various dilutions of plant extracts. The mixtures were incubated for $30 \mathrm{~min}$ at $37^{\circ} \mathrm{C}$. Then $0.1 \mathrm{~mL}$ of the mixture was added to $0.3 \mathrm{~mL}$ of citrated plasma and the clotting time recorded. In control tubes, plasma was incubated with either venom alone or plant extract alone. Neutralization was expressed as effective dose (ED), defined as the ratio $\mu \mathrm{L}$ antivenom (plant extracts)/mg venom at which the clotting time increased three times as compared to the clotting time of plasma incubated with two MCD of venom alone.

Fibrinolytic activity: A modified plaque assay was used (Laing et al., 1992). The minimum fibrinolytic concentration was defined as the concentration of venom that induced a fibrinolytic halo of $10 \mathrm{~mm}$ diameter. Neutralization experiments were performed by incubating constant amount of venom with varying amounts of $A$. calamus and Withania somnifera plant extracts at $37^{\circ} \mathrm{C}$ for $1 \mathrm{~h}$. After incubation, the mixture was applied to the wells in the plaque. After $18 \mathrm{~h}$ of incubation at $37^{\circ} \mathrm{C}$, fibrinolytic halos were measured.

Double immunodiffusion. The interaction of $A$. calamus and $W$. somnifera root extracts against $B$. caeruleus venom was evaluated using double immunodiffusion technique (Ouchterlony, 1953). Agar (1 g) was boiled in $100 \mathrm{~mL}$ water in microwave oven. The agar solution was then allowed to cool to $45^{\circ} \mathrm{C}$ and then $3.5 \mathrm{~mL}$ of it was pipetted onto a precoated slide. The slide was left to solidify at room temperature after which four holes were punched out using a gel puncher. The plugs of agar were removed from each well with a Pasteur pipette attached to a vacuum line. The test was conducted by pipetting $20 \mu \mathrm{L}$ of $B$. caeruleus venom $(10 \mathrm{mg} / \mathrm{mL})$ and $20 \mu \mathrm{L}$ of crude plant extract $(100 \mathrm{mg} / \mathrm{mL})$ into wells 1 and 2, respectively, followed by incubation overnight at room temperature in a humid chamber. The slide was examined for precipitation lines.

Statistical analysis. Statistical evaluation was performed using XL stat 2008 and SPSS 10 Softwares. $\mathrm{P}<0.005$ was considered statistically significant.

\section{Results and Discussion}

The lethal toxicity $\left(\mathrm{LD}_{50}\right)$ of the venom and of the two root extracts was assessed using $18 \mathrm{~g}$, Balb/c strain mice. About $3 \mu \mathrm{g}$ of the venom was found to be $\mathrm{LD}_{50}$ for $18 \mathrm{~g}$ mice. About $1.2 \mathrm{mg}$ and $1.4 \mathrm{mg}$ was found to be the lethal toxicity $\left(\mathrm{LD}_{50}\right)$ for $A$. calamus and $W$. somnifera root extracts, respectively. Neutralization of lethality was carried out by preincubating constant amount of venom with various dilutions of the two root extracts prior to injection. It was found that $0.12 \mathrm{mg}$ of A. calamus and $0.15 \mathrm{mg}$ of $W$. somnifera root extracts were able to completely neutralize the lethal activity of $2 \mathrm{LD}_{50}$ of the B. caeruleus venom (Table 1, Fig. 1). In edema forming activity, $2 \mu \mathrm{g}$ of the venom induced edema formation within $3 \mathrm{~h}$ which is considered as $100 \%$ activity. The edema was reduced down to $20 \%$ when $4000 \mu \mathrm{L}$ of plant extracts/mg venom was given. There was no further reduction in the percentage of edema even when there was an increase in antivenom dose (Fig. 2). In the case of haemorrhagic activity, $2 \mu \mathrm{g}$ of venom produced a haemorrhagic spot of $10 \mathrm{~mm}$ diameter (MHD). Both plant extracts were able to neutralize the haemorrhage induced by the venom. In phospholipase activity (PLA2), $10 \mu \mathrm{g}$ of B. caeruleus venom was able to produce $11 \mathrm{~mm}$ diameter haemolytic 
halo, which is considered to be $1 \mathrm{U}(\mathrm{U} / 10 \mu \mathrm{g})$. Both root extracts were capable of inhibiting PLA2 dependent haemolysis of sheep RBC's induced by the venom in a dose dependent manner (Table 2). Minimum coagulant dose (MCD) was determined and it was found that $40 \mu \mathrm{g}$ of the viper venom clotted $0.3 \mathrm{~mL}$ human citrated plasma within $60 \mathrm{sec}$. In the neutralization assay, the absence of clot formation shows the neutralizing ability of both the plant extracts. High concentration of venom caused rapid clotting that required very high concentration of anti-venom to neutralize. The fibrinolytic effect was effectively antagonized by both the plant

Table 1. Neutralization of $B$. caeruleus venom induced lethality by $A$. calamus and $W$. somnifera root extracts

\begin{tabular}{lll}
\hline \hline Plant extracts & $\begin{array}{l}\text { Concentration of } \\
\text { B. caeruleus } \\
\text { venom }(\mu \mathrm{g})\end{array}$ & $\begin{array}{l}\text { Neutralization of } \\
\text { venom by } \\
\text { plant extracts } \\
\left(\mathrm{ED}_{50} \mathrm{in} \mathrm{mg}\right)\end{array}$ \\
\hline Acorus calamus & $6\left(2 \mathrm{LD}_{50}\right)$ & $0.12 \mathrm{mg}$ \\
Withania somnifera & $6\left(2 \mathrm{LD}_{50}\right)$ & $0.15 \mathrm{mg}$ \\
\hline \hline
\end{tabular}

Table 2. Phospholipase activity of B. caeruleus venom and its neutralization by $A$. calamus and $W$. somnifera root extracts

\begin{tabular}{lll}
\hline \hline Plant extracts & $\begin{array}{l}\text { Dose of } \\
\text { B. caeruleus } \\
\text { venom }(\mu \mathrm{g})\end{array}$ & $\begin{array}{l}\text { Neutralization of } \\
\text { venom by plant } \\
\text { extracts (ED } 50 \mathrm{in} \mathrm{mg})\end{array}$ \\
\hline A. calamus & 10 (1 Unit) & $0.11 \mathrm{mg}$ \\
W. somnifera & 10 (1 Unit) & $0.14 \mathrm{mg}$ \\
\hline \hline
\end{tabular}

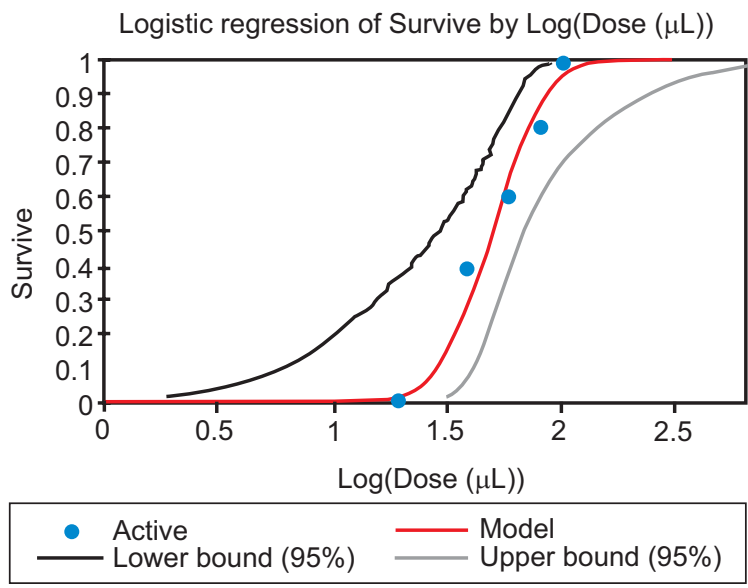

Acorus calamus extract. The $\mathrm{ED}_{50}$ of $A$. calamus and $W$. somnifera root extracts against the venom were found to be 0.4 and $0.7 \mathrm{mg}$, respectively. In Double Immunodiffusion test, a visible precipitin line was form between the venom and the plant extracts showing that plant extracts possess potent snake venom neutralizing compounds.

Snakebites are encountered all over the country with a rural/urban ratio of 9:1. They are more common during monsoon and post monsoon seasons. Many of the susceptible populations are poor living below poverty line, living in rural areas with less access to health care. About $10 \%$ of snakebite deaths are among the victims who come to the hospital and about $90 \%$ die outside, having under-gone other remedies like mantra, magic, and so on. The hospital stay varies from 2 to 30 days, the median being 4 days. The in-hospital mortality varies from 5 to $10 \%$, and the causes are acute renal failure, respiratory failure, sepsis, bleeding and others (TNHSP, 2008). Antivenom against snakes bites are lacking in the rural areas of coastal region. The most common and effective method of treating snake bite victims is through administration of antivenom, a serum made from the venom of the snake (Gomes et al., 2010). Although, use of plants against the effects of snakes bite has been long recognized, more scientific attention has been given during the last 20 years. In our present study we assessed the antivenom potential of $A$. calamus and $W$. somnifera root extracts against $B$. caeruleus venom. The neutralization ability of snake antivenoms is still assessed by the traditional in vivo lethality assay (minimum effective dose $\mathrm{ED}_{50}$ ), comparable to those used for bacterial antitoxins, usually performed in mice

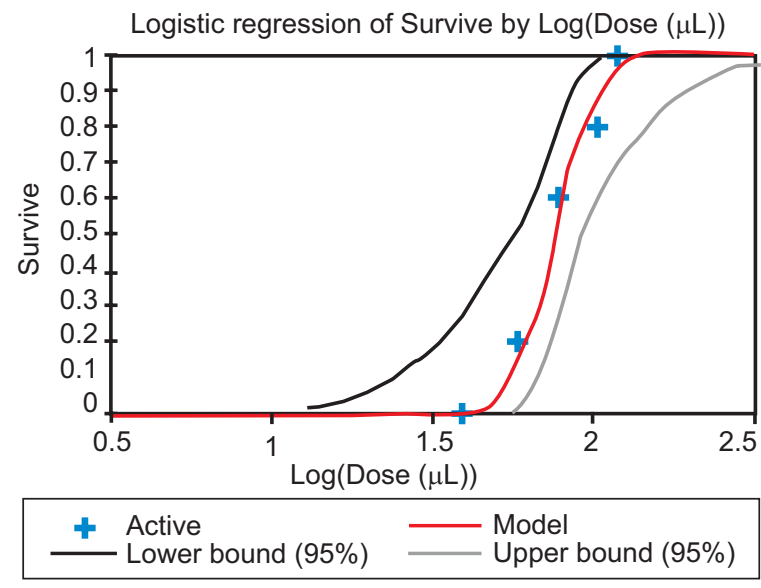

Withania somnifera

Fig. 1. Dose response curve for neutralization of lethality by $A$. calamus and $W$. somnifera root extracts against B. caeruleus venom. 

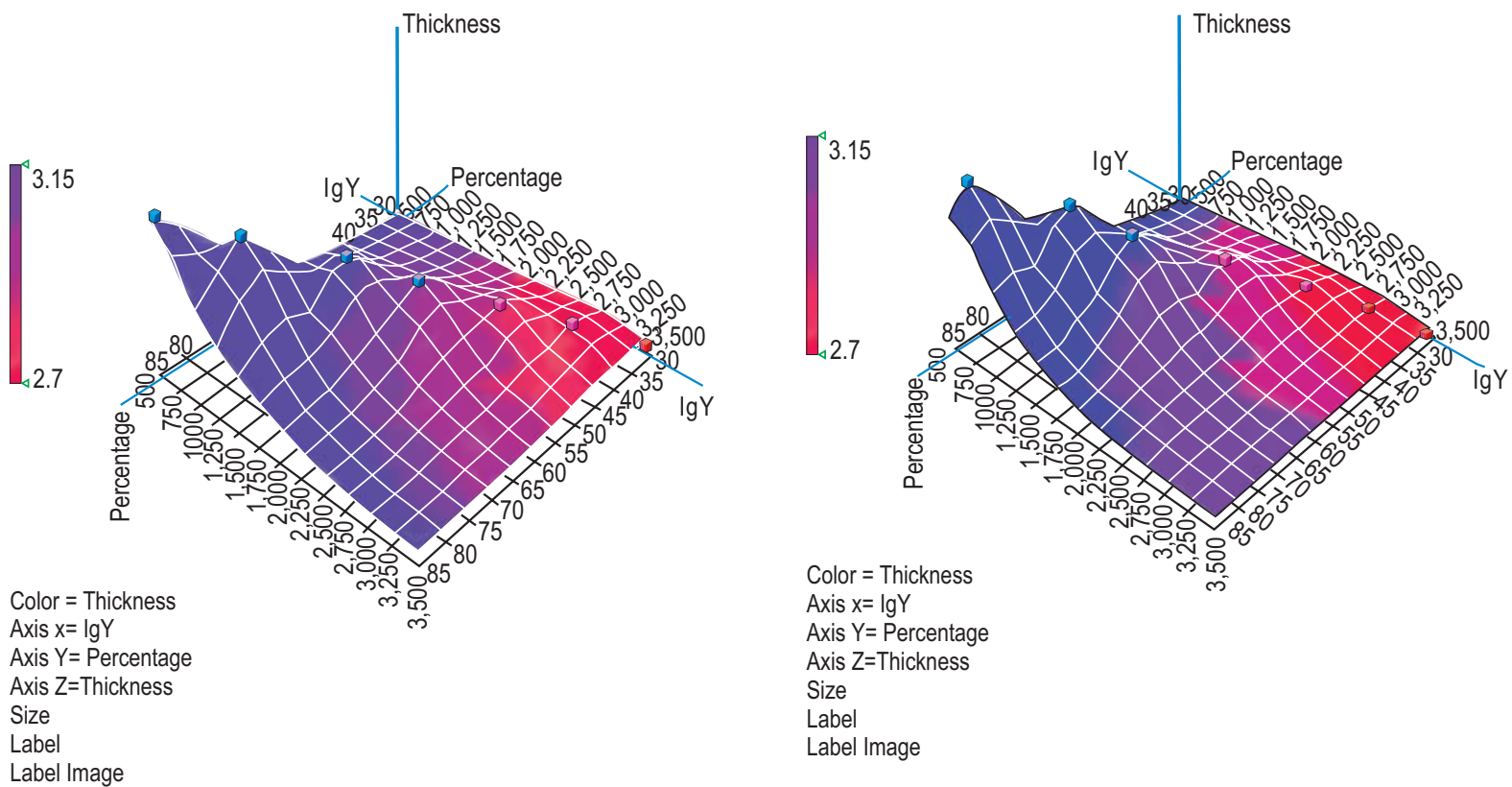

Fig. 2. Neutralization of edema induced by B. caeruleus venom by (A) A. calamus and (B) W. somnifera root extracts in experiments with pre-incubation. Results presented as mean $\pm \mathrm{SE}(\mathrm{N}=3) . \mathrm{P}<0.005$ at all antivenoms/venom ratios.

(WHO, 2004). Herbal compounds that possess antisnake venom activity are tested in experimental animal models through administering in different ways: (A) venom-herbal compounds mixed together, (B) herbal compounds followed by venom and (C) venom followed by herbal compounds (Gomes et al., 2010). In the present preliminary work the anti venom properties of plant extracts were tested by pre-incubation method venom-herbal compounds mixed together and tests for various pharmacological activities like lethality, edema forming activity, hemorrhagic activity, phospholipase activity (PLA2), procoagulant activity caused by B. caeruleus venom were undertaken. Neutralization studies can be performed by incubating of venom and plant extracts prior to testing (pre-incubation method). The results showed that both the plant extracts were capable of neutralizing the lethality induced by the venom. The venom showed the presence of PLA2 enzymes through producing haemolytic haloes in indirect haemolytic assays. Both the plant extracts were capable of inhibiting PLA2 dependent haemolysis of sheep RBCs in a dose dependent manner. The medicinal plants, Camellia sinensis L. and Cordia verbenacea effectively neutralized the phospholipase A2 activity induced by snake venoms (Ticli et al., 2005; Fattepur and Gawad, 2004). Edema-forming activity was assessed for B. caeruleus venom and both plant extracts were found to be effective in neutralization of edema induced by venom. There was a significant decrease in the edema (footpad thickness) when there was an increase in the antivenom (plant extract) concentration. Procoagulant activity induced by the venom was studied using human citrated plasma and both the root extracts were found to be effective in the neutralization of procoagulant activity. The present experimental results indicate that A. calamus and $W$. somnifera root extracts were effective in neutralizing the main toxic and enzymatic effects of B. caeruleus venom. The anti-venom properties of both the plant extracts were potent enough to neutralize the lethality and various pharmacological activities of venom. The result from this preliminary study indicates that both the plant extracts have the potential to be used for therapy in patients with snakebite envenomation. Further investigations are needed for identification and purification of the active components involved in the neutralization of the snake venom.

\section{References}

Alam, M.I., Gomes, A. 2003. Snake venom neutralization by Indian medicinal plants (Vitex negundo and Emblica officinalis) root extracts. Journal of Ethnopharmacology, 86: 75-80.

Bawaskar, H.S. 2004. Snake venoms and antivenoms: critical supply issues. Journal of the Association of Physicians of India, 52: 11-13. 
Daduang, S., Sattayasai, N., Sattayasai, J., Tophrom, P., Thammathaworn, A., Chaveerach, A., Konkchaiyaphum, M. 2005 Screening of plants containing Naja naja siamensis cobra venom inhibitory activity using modiWed ELISA technique. Analytical Biochemistry, 341: 316-325.

Fattepur, S.R., Gawade, S.P. 2004. Preliminary Screening of Herbal Plant Extracts for Anti-venom activity against Common Sea Snake (Enhydrina schistosa) Poisoning. Pharmacognosy Magazine, 16: 56-60.

Gomes, A., Das, R., Sarkhel, S., Mishra, R., Mukherjee, S., Bhattacharya, S., Gomes, A. 2010. Herbs and herbal constituents active against snake bite. Indian Journal of Experimental Biology, 48: 865-878.

Gutierrez, J.M., Avila, C., Rojas, E., Cerdas, L. 1988. An alternative in vitro method for testing the potency of the polyvalent antivenom produced in Costa Rica. Toxicon, 26: 411-413.

Houghton, P. J., Osibogun, I. M. 1993. Flowering plants used against snakebite. Journal of Ethnopharmacology, 39: 1-29.

Hung, Y.C., Sava, V., Hong, M.Y., Huang, G.S. 2004. Inhibitory effects on phospholipase A2 and antivenin activity of melanin extracted from Thea sinensis Linn. Life Sciences, 74: 2037-2047.

Laing, G. D., Theakston, R.D.G., Leite, R.P., Da Silva, W.D.D., Warrell, D.A. 1992. Comparison of the potency of three Brazilian Bothrops antivenoms using in-vivo rodent and in-vitro assays. Toxicon, 30: 1219-1225.

Lomonte, B., Tarkowski, A., Hanson, L.A. 1993. Host response to Bothrops asper snake venom: analysis of edema formation, inflammatory cells, and cytokine release in a mouse model. Inflammation, 17: 95-105.

Meenatchisundaram, S., Michael, A. 2010. Antitoxin activity of Mucuna pruriens aqueous extracts against Cobra and Krait venom by in vivo and in vitro methods. International Journal of PharmTech Research, 2: 870-874.

Meenatchisundaram, S., Parameswari, G., Michael, A. 2009a. Studies on antivenom activity of Andrographis paniculata and Aristolochia indica plant extracts against Daboia russel venom by in vivo and in vitro methods. Indian Journal of Science and Technology, 2: 76-79.

Meenatchisundaram, S., Priyagrace, S., Vijayaraghavan, R., Velmurugan, A., Parameswari, G., Michael, A. 2009b. Antitoxin activity of Mimosa pudica root extracts against Naja naja and Bangarus caerulus venom. Bangladesh Journal of Pharmacology, 4:
105-109.

Otero, R., Fonnegra, R., Jimenez, S.L., Nunez, V., Evans, N., Alzate, S.P., Garcia, M.E., Saldarriaga, M., Del Valle, G., Osorio, R.G., Diaz, A., Valderrama, R., Duque, A., Velez, H.N. 2000. Snakebites and ethnobotany in the northwest region of Colombia: I. Traditional use of plants. Journal of Ethnopharmacology, 71: 493-504.

Ouchterlony, O. 1953. Antigen antibody reactions in gels. IV. Types of reactions in co-ordinated systems of diffusion. Acta Pathologica et Microbiologica Scandinavia, 32: 231-240.

Rojas, E., Quesada, L., Arce, V., Lomonte, B., Rojas, G., Gutierrez, J.M. 2005. Neutralization of four Peruvian Bothrops sp. snake venoms by polyvalent antivenoms produced in Peru and Costa Rica: preclinical assessment. Acta Tropica, 93: 85-95.

Theakston, R.D.G., Reid, H.A. 1983. Development of simple standard assay procedures for the characterization of snake venoms. Bulletin of the World Health Organization, 61: 949-956.

Ticli, F.K., Hage, L.I., Cambraia, R.S., Pereira, P.S., Magro, A.J., Fontes, M.R., Stabeli, R.G., Giglio, J.R., Franca, S.C., Soares, A.M., Sampaio, S.V. 2005. Rosmarinic acid, a new snake venom phospholipase A2 inhibitor from Cordia verbenacea (Boraginaceae): Antiserum Action Potentiation and Molecular Interaction, Toxicon, Official Journal of the International Society of Toxinology, 46: 318-327.

TNHSP 2008. Handbook on Treatment Guidelines for Snake Bite and Scorpion Sting. Tamil Nadu Health Systems Project, Health and Family Welfare Department, Government of Tamil Nadu, Chennai, India.

Uhegbu, F.O., Elekwa, I., Ukoha, C. 2005 Comparative efficacy of crude aqueous extract of Mangifera indica, Carica papaya and sulphadoxine pyrimethamine on the mice infested with malaria parasite in vivo. Global Journal of Pure Applied Science, 11: 399- 401.

WHO 1981. Progress in Characterization of Venoms and Standardization of Antivenoms. World Health Organization (Offset Publication Number-58, Geneva, Switzerland.

Yamakawa, M., Nozaky, M., Hokama, Z. 1976. Fractionation of sakishimahabu (Trimeresurus elegans) venom and lethal, hemorrhagic and edema-forming activities of the fractions. In: Toxins: Animal, plant and Microbial. Plenum Press, vol. 1, pp. 97-109. A. Ohsaka, K. Hayashi and Y. Sawai (eds.), New York, USA. 